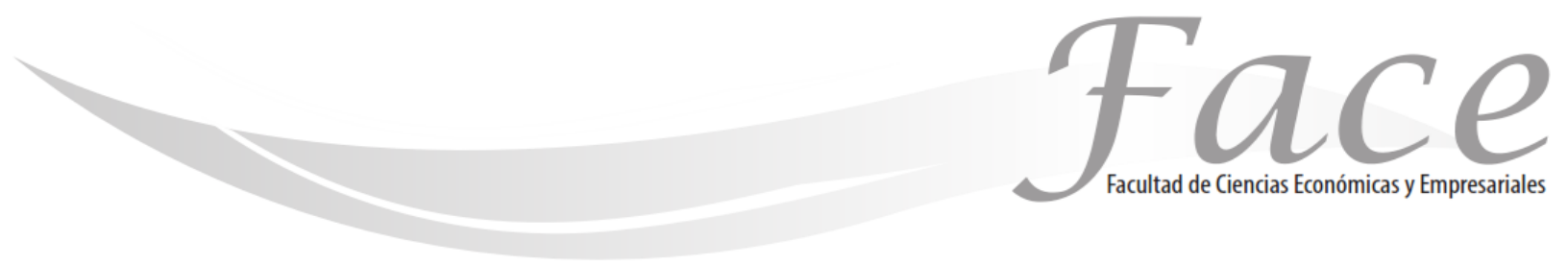

ISSN Impreso: 1794-9920

ISSN Electrónico: 2500-9338

Volumen 17-N¹

Año 2017

Págs. $55-64$

\title{
RETOS DEL EMPRENDEDOR EN MEXICO
}

\author{
Rebeca Almanza Jiménez ${ }^{*}$ \\ Enlace ORCID: http://orcid.org/0000-0002-5177-022X \\ Patricia Calderón Campos ${ }^{* *}$ \\ Enlace ORCID: http://orcid.org/0000-0001-8408-8406 \\ José G. Vargas Hernández $z^{* \star *}$ \\ Enlace ORCID: https://orcid.org/0000-0003-0938-4197
}

Fecha de Recepción: Enero 3 de 2017

Fecha de Aprobación: Abril 28 de 2017

\section{Resumen:}

A partir del siglo XX ha existido particular interés por estudiar y entender el papel del emprendedor en México debido a que este beneficia a la economía del país y contribuye al desarrollo económico y social del territorio nacional por lo que en el presente proyecto de investigación se propone identificar los retos del emprendedor en México, el cual inicia con una breve introducción del tema objeto de estudio, posteriormente se incorpora el marco teórico el cual comprende la conceptualización del termino emprendedor desde la óptica de distintos autores así como su desarrollo teórico que analiza el emprendimiento en México y el perfil del emprendedor, dentro del cual se describen las competencias que favorecen al emprendedurismo como son las personales, sociales y profesionales, posteriormente se analizan los retos del emprendedor, y por último se incorporan las conclusiones.

Palabras Claves: Competencias, emprendedor, perfil, retos.

JEL: D23, 121, M12, M13

\footnotetext{
* Doctora en administración. Instituto Tecnológico de Lázaro Cárdenas - Avenida Melchor Ocampo No. 2555, Ciudad Lázaro Cárdenas Michoacán, C.P. 60950, Tel (753) 210-40 y 71977. Correos electrónicos: rebeca_aj@hotmail.com, itlac_aj@hotmail.com

** Doctora en Administración. Profesora del Instituto Tecnológico de Lázaro Cárdenas - Lázaro Cárdenas Michoacán. Cp. 60954. Correos electrónicos: calderon7101@yahoo.com.mx, patriciatecmx@gmail.com

*** M.B.A.; Ph.D. CUCEA, Universidad de Guadalajara - Periférico Norte 799 Edif. G201-7; Los Belenes; C.P. 45100, Zapopan, Jalisco, México, Tel. +523337703340 Ext. 25685. Correos electrónicos: jvargas2006@gmail.com, jgvh0811@yahoo.com, josevargas@cucea.udg.mx
} 


\title{
CHALLENGES OF THE ENTREPRENEUR IN MEXICO
}

\begin{abstract}
Since the twentieth century there has been particular interest in studying and understanding the role of the entrepreneur in Mexico because it benefits the country's economy and contributes to the economic and social development of the national territory, so that in the present research project is proposed Identify the challenges of the entrepreneur in Mexico, which begins with a brief introduction of the subject of study, later incorporates the theoretical framework which includes the conceptualization of the term entrepreneur from the perspective of different authors as well as their theoretical development that analyzes the entrepreneurship In Mexico and the profile of the entrepreneur, which describes the competencies that favor entrepreneurship such as personal, social and professional, then analyze the challenges of the entrepreneur, and finally incorporate the conclusions.
\end{abstract}

Keywords: Competence, entrepreneur, profile, challenges.

JEL: D23, 121, M12, M13

\section{DESAFIOS NO MÉXICO EMPREENDEDOR}

\section{Resumo}

No início do século XX, tem havido particular interesse em estudar e compreender o papel do empreendedor no México, porque isso beneficia a economia e contribui para o desenvolvimento econômico e social do país, de modo neste projeto de pesquisa é proposto identificar os desafios do empreendedor no México, que começa com uma breve introdução do tema em estudo, em seguida, o quadro teórico que inclui a conceituação do termo empreendedor a partir da perspectiva de diferentes autores e seu desenvolvimento teórico que analisa o empreendedorismo Incorporated no México e no perfil do empreendedor, dentro do qual os poderes que favorecem o empreendedorismo como desafios pessoais, sociais e profissionais do empresário posteriormente analisadas e, finalmente, as conclusões são incorporadas são descritos.

Palavras-chave: Habilidades, perfil empreendedor de desafios.

JEL: D23, 121, M12, M13 


\section{INTRODUCCIÓN:}

Durante las últimas décadas se ha observado un creciente interés sobre el emprendedurismo en México en virtud de que este constituye el camino hacia el crecimiento economico y la generación de empleos lo que favorece a todo tipo de instituciones ya sean estas públicas o privadas, pequeñas, medianas 0 grandes y genera desarrollo en los mercados nacional 0 internacional (Soriano \& Huarng, 2013).

El termino emprendimiento se ha relacionado específicamente con la innovación. Schumpeter es considerado un pionero en el análisis económico. El percibía al emprendedor como una persona extraordinaria que promovía nuevas innovaciones o combinaciones. Sostenía que la función de los emprendedores es reformar o revolucionar el patrón de la producción al explotar una inversión o más comúnmente, una posibilidad técnica no probada.

Hacerse cargo de estas cosas nuevas es difícil y constituye una función económica distinta, primero, porque se encuentran fuera de las actividades rutinarias $y$, en segundo lugar, porque el entorno se resiste de muchas maneras desde un simple rechazo a financiar o comprar una idea nueva, hasta el ataque físico al hombre que intenta producirlo (Schumpeter, 1935).

Al respecto, Drucker (1986), expresa que el empresario innovador se basa en los mismos principios, aunque el empresario sea una gran institución o un individuo que comienza solo su empresa arriesgadamente. No hay diferencia, si la empresa es comercial 0 es una organización de servicios públicos; ni siquiera si la empresa es gubernamental 0 no, las reglas son exactamente las mismas; lo que sirve y lo que no sirve, las clases de innovación y donde buscarlas.

\section{MARCO TEÓRICO:}

El término emprendedor proviene de la voz castellana "emprender" que proviene del latín in, en y prenderé coger o tomar, aplicándose inicialmente en España como en otros países a lo que ahora serian llamados aventureros, principalmente militares, sentido que evoluciono posteriormente a tener connotaciones comerciales. La palabra fue definida por primera vez en el Diccionario de autoridades de 1732, todavía con esas connotaciones, como: La persona que emprende y se determina hacer y ejecutar, con resolución y empeño alguna operación considerable y ardua, y de envergadura que requiere esfuerzo y dedicación.

En inglés la palabra Entrepreneur, que en realidad es una palabra de origen francés significa libre y llanamente empresario (Puchol, 2001). Esta palabra era usada para referirse a aventureros que como Cristóbal Colon arribaron al nuevo mundo; sin saber con certeza que esperar en él. El emprendedor es sinónimo de inteligencia y actitud (RAE, 2014).

En 1755, Richard Cantillon cambia definitivamente ese sentido de la apalabra transformándola en la voluntad o capacidad de enfrentar la incertidumbre. Cantillon postula que el resultado de toda actividad es incierto, implica un riesgo, y alguien tiene que asumirlo con la esperanza de recompensa en el futuro y utiliza el termino Entrepreneur para designar a ese individuo, con lo que su significado pasa a ser tomador de riesgos, en lugar de ser alguien que tomaba un salario.

Posteriormente el término emprendedor fue usado para identificar a quien iniciaba una empresa y fue ligado a empresarios innovadores (Castillo, 1999), pero también puede relacionarse con cualquier persona que decide llevar adelante un proyecto, aunque este proyecto no tenga fines económicos (Formichella, 2004). El emprendedor tiene las características de aquellas personas cuyas capacidades se encuentran comprometidas a hacer cosas que mejoren los resultados de la organización (Jericó, 2006). El emprendedor está en posesión de habilidades repetibles que no dependen del tamaño físico (Coyle, 2009).

Hay distinciones entre emprendedor, inversionista y empresario según Zorrilla (2009). Así emprendedor es quien tiene la idea, el concepto de un producto o servicio a realizar; inversionista es quien pone a disposición el capital necesario, para el sostenimiento inicial y la puesta en marcha de un negocio; $y$, finalmente y no menos importante, el empresario, es la persona que se encarga de administrar y rendir cuentas del negocio.

Schumpeter (1942) citado por Borjas (2003) plantea al emprendedor en función de reformar o revolucionar el patrón de producción al explotar una invención o más comúnmente, para producir un nuevo producto 0 transformar uno ya existente, las cuales son actividades responsables de la prosperidad que cambian el organismo económico. El concepto de emprendedor es un proceso de desarrollo caracterizado por la innovación constante (Pereira, 2003). Para McClellan (1989), también citado por Borjas (2003), la motivación del logro es el origen del emprendimiento y la define como un proceso mental enfocado al planteamiento y búsqueda del progreso, excelencia, innovación y esfuerzo. 
El emprendedor busca asumir responsabilidades en situaciones difíciles, que puede controlar, por el deseo de emprender un negocio. Por su parte, Gibb (1988) afirma que los emprendedores juegan un papel fundamental en el proceso innovador, dado su búsqueda y procesamiento de nuevas oportunidades. El emprendedor es una persona que toma decisiones sobre la base de lo complicado del riesgo, y el ingenio usado (Rodríguez \& Jiménez, 2005).

El emprendedor es un agente productivo que compra servicios de los demás agentes, los combina en el proceso productivo para generar productos que tengan valor superior a la suma de los servicios utilizados (Gámez, 2008). Al respecto, Valdaliso y López (2000) aseveran que emprendedor es la persona que asume el riesgo y es sumamente inteligente. El emprendedor tiene cualidades de imaginación, audacia y sorpresa. Kirzner (1997), al respecto considera que emprendedor es aquel que desea especular en una situación de incertidumbre, respondiendo a las señales del mercado con respecto a precios, ganancias y pérdidas. Es aquel sujeto que descubre en el mundo del conocimiento imperfecto una oportunidad que otros no han percibido.

\subsection{Desarrollo Teórico}

\section{Él emprendimiento en México}

México enfrenta muchos y muy variados retos. Sin embargo, el de mayor trascendencia es el que se refiere a ampliar nuestra capacidad de generación de riqueza, de manera que se permita incluir en un México prospero a los millones de mexicanos que están actualmente excluidos y que viven en condiciones de pobreza. Este es el reto principal de esta generación. La oportunidad radica en que se cuenta con una población joven y un bono demográfico que, bien utilizado, puede hacer viable el cambio requerido.

Este proceso requiere de la participación y el esfuerzo de todos los sectores y también exige una clara estrategia en donde se defina una visión y se establezcan prioridades nacionales claras. Una de las prioridades debe de ser ampliar significativamente el número y la calidad de las empresas del país. "Las empresas de alto impacto son empresas de reciente creación, generalmente asociadas a alguna innovación y con un alto y evidente potencial de crecimiento.

Son usualmente ideas que se generan en respuesta a alguna necesidad patente que resuelven de una manera diferenciada a las soluciones actuales, proveyendo de mayores beneficios a sus clientes" de acuerdo a Dantus (2013). Estas empresas para ser exitosas, requieren de una estrategia clara y una detallada planeación financiera que les permita conseguir capital para acelerar su crecimiento y generar empleo con una base tecnológica y que tengan impactos relevantes en la economía.

Algunos de los ejemplos exitosos más conocidos son: Apple, Microsoft, Google, Facebook, etc., a nivel internacional y en México se pueden citar entre otras a: Corona extra, Telmex, Telcel, Televisa, Tiendas Electra, Bimbo, Cemex, Grupo Banorte, Grupo Inbursa, Bodega Aurrera y Oxxo, Liverpool, Grupos Carso, entre otras. Estas empresas son, hoy en día, inmensas corporaciones de alto valor para la economía. Algún día, hace pocos años, fueron simplemente una idea y luego un emprendimiento. El ganador indiscutible entre los mexicanos es Carlos Slim, con tres compañías entre las más grandes del mundo.

\section{Perfil del emprendedor en México}

Actualmente se tiene la creencia de que en México los negocios exitosos solo están hechos para las grandes empresas o empresarios extranjeros que poseen mucho capital. Esto no es totalmente cierto, ya que el país poco a poco ha ido creciendo en cuanto a empresas innovadoras que han favorecido el sistema económico nacional. Ciertamente son las empresas grandes las que logran el desarrollo de las actividades innovadoras hasta un 50\%, pero las empresas pequeñas y las del tipo pymes llegan a cubrir el otro $50 \%$ restante.

En el caso particular de México donde se han manifestado más casos de empresas innovadoras han sido en las siguientes áreas: software, aeroespacial, automotriz, alimentos, empresas verdes, viviendas, equipo médico y comercio electrónico. Un $54 \%$ de estos sectores innovadores se encuentran localizados en empresas del Distrito Federal de las cuales el $23 \%$ son enfocadas a software, un $20 \%$ a tecnología verde y un $11 \%$ a alimentos.

Estos números permiten conocer y distinguir que tipos de negocios establecer en México, ya sea como inversionista nacional o extranjero. Además la gran mayoría de estos sectores se han establecido por profesionistas so personas profesionales con conocimiento en su negocio. Dentro de las empresas innovadoras mexicanas en el ramo de la tecnología se encuentran: Tiendas Kit, RFID México, Slang (videojuegos), Snake \& Eagle (simuladores en tercera dimensión), Zerta (equipo médico). Cada una de estas empresas se ha logrado establecer en el país con gran éxito y abriendo muchas oportunidades gracias a la labor de emprendedores innovadores que han tenido la visión de implementar cosas nuevas al país sin miedo alguno.

Para esto se han identificado ciertas características asociadas al perfil del emprendedor, dentro de las cuales se citan las siguientes: 
Comenzar a innovar a una edad aproximada de 35 años, cuenta con un título universitario, proviene de una familia que lo puede apoyar económicamente para financiar su educación e invertir dentro de la empresa, posee un nivel socioeconómico alto, cuenta con experiencia laboral en el sector privado de varios años, lo cual le permite posteriormente realizar emprendimiento con relaciones sociales que le ayudan a obtener inversionistas en sus proyectos, el capital con el que cuentan es de ahorros 0 bien de préstamos familiares, la vida promedio de sus empresas es de 10 años aproximadamente, su objetivo es la innovación de su producto que abra un mercado novedoso a nivel nacional y buscan apoyo en aquellos que tienen conocimientos especializados para la solución de problemas. Para llegar a ser un emprendedor debe haber un trasfondo y una serie de hechos que lo encaminaron a ser exitoso como son el historial educativo, que se remonta a tener padres con estudios superiores,

\subsection{Competencias que Favorecen el Emprendedurismo}

El emprendedor se propone una obra, un proyecto. Es decir, tiene un objetivo, una meta, quiere conseguir algo que implica cierto grado de dificultad. El emprendedor va a cometer acciones y a gestionar situaciones con cierto grado de complejidad y dificultad. Por ello ha de poseer los recursos que le permitan saber afrontar estos miedos de cara a sortear los peligros e incertidumbre. Coyle (2009) define al emprendedor como la posesión de habilidades repetibles que no dependen del tamaño físico.

El término de competencias en el mundo industrializado no es nuevo. En México empezó a aplicarse a mediados de los 90's. Impulsada por el Gobierno Federal, a través del Consejo de Normalización y Certificación de Competencia Laboral CONOCER (1997). Este organismo es el encargado de establecer un sistema de certificación de la capacidad o "competencia" laboral de los trabajadores, con el fin de impulsar su desarrollo con base en estándares de calidad del desempeño; este sistema de competencias, debería de servir también para orientar la educación y la capacitación hacia las necesidades de los mercados productivo y laboral.

Existen múltiples definiciones de competencias de las cuales algunos autores las conceptualizan como: "Repertorios de conocimientos que algunos dominan mejor que otros, lo que les hace eficaces en una situación determinada" (Levy-Leboyer, 1997: 13). Por su parte Perrenoud (2004) conceptualiza las competencias como una aptitud para enfrentar de manera eficaz una familia de situaciones análogas, movilizando a consciencia y de manera a la vez rápida, pertinente y creativa, múltiples recursos cognitivos tales como saberes, capacidades, valores, actitudes, esquemas de percepción de evaluación y de razonamiento. Las competencias que favorecen el emprendedurismo son: competencias personales, competencias sociales y competencias profesionales las cuales se describen a continuación:

\section{Competencias personales}

Las competencias personales desarrollan conductas observables en determinada área de su vida en donde se desenvuelve. Una persona presenta un perfil de competencias alto cuando demuestra las cualidades requeridas para realizar determinadas tareas. Son características permanentes de las personas, se ponen de manifiesto cuando se ejecuta una tarea 0 un trabajo no están asociadas con el éxito, sino que se asume que realmente lo causan, pueden ser generalizadas a más de una actividad y combinan lo cognoscitivo, lo afectivo y lo conductual (Vargas, 2001).

La competencia personal, es además, la capacidad subyacente en una persona que está causalmente relacionada con el desempeño, referido a un criterio superior o efectivo en un trabajo o situación (Spencer \& Spencer, 1993). Estas características de un individuo guardan una relación causal con el desempeño efectivo 0 superior en el puesto, tales como motivos, rasgos de personalidad, habilidades, aspectos de autoimagen 0 un conjunto de conocimientos que un individuo está usando (McClellan, 1989). Las competencias son consideradas como la capacidad para responder exitosamente a una demanda, tarea o problemas complejos movilizando y combinando recursos personales cognitivos y no cognitivos y del entorno (OCDE, 2005).

Las habilidades se encuentran integradas en la persona como hábitos de conducta, como pautas de acción sistematizadas y convertidas, modelos que se repiten no de manera consciente se convierten en competencias personales, sociales y profesionales. Es decir, deben de estar guiadas en saber algo y querer hacer algo. Dentro de las competencias personales, Mercader (1998) distingue las asociadas al conocimiento de sí mismo, autorrealización y autocontrol.

\section{- Conocimiento de sí mismo}

El conocimiento de sí mismo se vincula con la necesidad de que el emprendedor se conozca, que tenga claramente definidos sus deseos e intereses, percepciones y motivaciones. Desarrollar el conocimiento de sí mismo implica saber que se cuenta con los recursos y que con su movilización se alcanzarán los resultados pretendidos. 
Senge (1997) identifica como visión personal o imagen de un futuro deseado.

En consecuencia, todo emprendedor debe establecer prioridades, definir metas e identificar una visión personal y profesional; para ello debe de autoevaluarse e identificar las fortalezas y debilidades que posee y su relación con las oportunidades y amenazas como factores internos que pudieran impedir el logro de metas.

\section{- Autorrealización}

Esta es definida por Senge (1997) como una necesidad fundamental en la adquisición de los propios ideales; es decir hacer realidad las visiones. Por su parte, Acosta (1998) considera que la autorrealización es la aspiración que se siente para ser mejores, por buscar la excelencia en lo que se realice, es una aspiración que motiva. Depende de la voluntad. Es la búsqueda permanente del propio crecimiento y desarrollo personal. La autorrealización es consecuencia de la motivación y esta lo impulsa al logro del éxito, apoyándose en su fuerza de voluntad y en la confianza de sus capacidades.

Según Mercader (1998), el ser humano tiene la capacidad de pensar con claridad, de mostrar decisión, de tener una mentalidad única que permite discernir entre las posibilidades reales, eligiendo la mejor alternativa para la solución de problemas. La autorrealización según este autor, no solo abarca alcanzar metas, sino de sentir satisfacción por el crecimiento que se experimenta; descubrir que se evoluciona en atención a las posibilidades y destrezas.

\section{- Autocontrol}

El autocontrol enfatiza la capacidad que debe de tener cualquier persona y, entre ellas el emprendedor, del manejo equilibrado de su inteligencia emocional. Mercader (1998) plantea que es necesario y trascendental que el emprendedor eduque su mente. La educación de la mente se fundamente en el cultivo y desarrollo de ciertos hábitos que clarifican el sentido de la vida y el rol en ella. Estos hábitos son: sonreír, aprovechar la vida a plenitud en tiempo agradable, y dejarse influenciar por las ideas positivas. El autocontrol permite al emprendedor controlar los pensamientos, sensaciones y sentimientos.

Las competencias del emprendedor en su componente personal a través del conocimiento de sí mismo, autorrealización y autocontrol, hacen posible el desarrollo de habilidades y capacidades para actuar teniendo presentes los retos que debe enfrentar, más las características 0 cualidades individuales dentro del componente humano que también está llamado a manejarlo equilibradamente.

\section{Competencias sociales}

La competencia social del emprendedor-empresario es la base sobre la que se organiza la acción del proyecto empresarial. La competencia social es lo que permite alcanzar la satisfacción de necesidades a través del acceso a los recursos y posibilidades que se encuentran en otras personas, en el entorno y en la sociedad. El relacionarnos con los demás, y saber hacerlo de forma adecuada y efectiva, se convierte en eje vertebrador de nuestra forma de pensar. Las habilidades sociales se encuentran definidas en tres componentes:

\section{- La empatía}

Se refiere a la habilidad cognitiva de una persona para comprender el universo emocional de la otra persona. Goleman, (1999). La empatía permite hacer referencia a la capacidad intelectual de todo ser humano para vivenciar la forma en que otro individuo se siente. Esta capacidad puede desembocar en una mejor comprensión de sus accione 0 de su manera de decidir determinadas cuestiones. La empatía otorga la habilidad para comprender los requerimientos, actitudes, sentimientos, reacciones y problemas de los otros, ubicándose en su lugar $\mathrm{y}$ enfrentando del modo masa adecuado sus reacciones emocionales.

\section{- Conocimiento de las convenciones sociales}

Es esencial conocer cuáles son los cánones que rigen en determinados foros. No es lo mismo ser un emprendedor que se va a manejar en el ámbito de las nuevas tecnologías, que un empresario que va a iniciar una actividad en un despacho de abogados mercantiles. El convencionalismo social es definido por el Diccionario de la Real Academia Española como una norma o practica admitida tácitamente, que responde a precedentes 0 a la costumbre (REA, 2014). Son reglas admitidas de trato social y hasta moralidad positiva. Suele definirse como reglas que se imponen en forma de costumbre en la sociedad o un grupo específico de ella.

La costumbre es el uso, ejercicio o práctica general de una cosa, es el modo de obrar de los emprendedores, si bien es cierto de que cada emprendedor es diferente, también lo es de que tienen unos hábitos en común como son: planear su día con anticipación antes de que comience el caos (llamadas telefónicas, citas reuniones), tienen una alimentación balanceada y hacen ejercicio, sirven a los demás, tienen metas claras, toman riesgos calculados, conocen sus fortalezas y debilidades, siguen aprendiendo, siempre estan buscando oportunidades y evalúan sus acciones y prioridades diariamente.

\section{- El factor situacional}


El momento concreto. Los factores y variables que condicionan de manera significativa la situación en la que se desenvuelve el contrato social. Las habilidades sociales incluyen los siguientes elementos y características: las habilidades sociales son conductas aprendidas, socialmente aceptadas y que, a su vez posibilitan la interacción con los demás, son conductas instrumentales necesarias para alcanzar una meta, en ellas se unen aspectos observables y aspectos de naturaleza cognitiva y afectiva no directa. La evaluación, interpretación y entrenamiento de las habilidades sociales debe estar en consonancia con el contexto social.

Las habilidades sociales más aceptadas en la actualidad según Perez-Santamarina, (1999), Torbay, Muñoz \& Hernández, (2001) y Portillo, (2001) son las siguientes: Escuchar, saludar, presentarse y despedirse, iniciar, mantener y finalizar una conversación, hacer y respetar peticiones, disculparse 0 admitir la ignorancia, defender los derechos, negociar, expresar y defender las opiniones incluido el desacuerdo, afrontar las críticas, hacer y recibir cumplidos, expresar amor, agrado y afecto, pedir el cambio de conducta del otro, cooperar y compartir, expresar y recibir emociones, dirigir a otros o solucionar conflictos, dar y recibir retroalimentación, realizar una entrevista, solicitar un trabajo y hablar en público entre otras.

El emprendedurismo social cuenta con diversas características dentro de las cuales destaca la sostenibilidad, ya sea con fines o sin fines de lucro, la promoción de la participación de las personas, la atención a problemas sociales con diversidad de objetivos, la búsqueda de un beneficio económico y una transformación social (Bargsted, 2013; Duarte \& Ruíz, 2009; Guzmán \& Trujillo, 2008).

Algunos autores mencionan que los emprendedores sociales poseen ciertas características y cualidades que los definen. Se trata de personas benevolentes, empáticas, que poseen un deseo de benevolentes, empáticas, que poseen un deseo de auto trascendencia y autodirección, son innovadores, proactivos y arriesgados (Arboleda \& Zabala, 2011; Curto, 2012; Orrego, 2008).

\section{Competencias profesionales}

Etimológicamente, el concepto de competencia proviene del latín competentia y dentro de las acepciones que le otorga la Real Academia Española se encuentran: incumbencia, pericia, aptitud, idoneidad para hacer algo 0 intervenir en un asunto determinado, oposición o rivalidad entre dos o más que aspiran a obtener la misma cosa 0 situación de empresas que rivalizan en un mercado ofreciendo o demandando un mismo producto o servicio. En consecuencia, se señalan tres significados: competencias como rivalidad o contienda, como incumbencia y como aptitud e idoneidad (RAE, 2014).

Las competencias profesionales son "Actuaciones integrales para identificar, interpretar, argumentar y resolver problemas con integridad y compromiso ético, movilizando los diferentes saberes: ser, hacer y conocer" (Tobón, 2010: 14). Las competencias profesionales definen el ejercicio eficaz de las capacidades que permiten el desempeño de una ocupación, respecto a los niveles requeridos en el empleo. Es algo más que el conocimiento técnico que hace referencia al saber y al saber- hacer. Engloba un conjunto de comportamientos, facultad de análisis, toma de decisiones, transmisión de información considerada necesaria para el pleno desempeño de la ocupación. Instituto Nacional de Empleo en España (INEM: 1995:21).

Por su parte (Díaz-Barriga, 2009) conceptualiza las competencias profesionales como la capacidad para hacer algo de modo idóneo que resulta de un proceso complejo de asimilación integrativa por parte del aprendiz de saberes conceptuales, saberes procedimentales y actitudes que se lleva cabo en la fase de ejercitación dentro del proceso enseñanza aprendizaje. "Idoneidad para realizar una tarea o desempeñar un puesto de trabajo eficazmente por poseer las calificaciones requeridas para ello" (OIT, 1993:37).

"Las competencias profesionales son el resultado de la integración, esencial y generalizada de un complejo conjunto de conocimientos, habilidades y valores profesionales que se manifiestan a través de un desempeño profesional eficiente en la solución de los problemas de su profesión pudiendo incluso resolver aquellos no predeterminados" (Forgas 2003:112). Posee competencia profesional quien dispone de los conocimientos, habilidades, aptitudes y actitudes necesarios para desempeñarse eficazmente en situaciones específicas de trabajo, lo cual le permite resolver, los problemas que se le presenten en el ejercicio de sus funciones, en forma autónoma y flexible, y está capacitado para colaborar en su entorno profesional y en la organización de su trabajo (Bunk, 1994).

\subsection{Retos del Emprendedor en México}

Emprender en México es complicado según la Organización de Cooperación y el Desarrollo Económicos (OCDE). Existen tres principales barreras para el establecimiento de nuevos negocios en el país: los monopolios públicos, los monopolios privados y el acceso al financiamiento. La falta de apertura para competir es una de las grandes barreras a la que los emprendedores se enfrentan. Los obstáculos dependen también de la organización económica de un país. 
En México la distribución inequitativa del ingreso y las oportunidades, aunado a un alto grado de economía informal y corrupción que alejan al emprendedurismo de actividades productivas e imponen gravámenes elevados a las inversiones extranjeras. Para que un emprendedor tenga impacto en la economía mexicana debe crear un negocio que repercuta en la generación de empleos y ofrezca productos y servicios innovadores.

"La innovación es una nueva idea que se aplica para iniciar - mejorar un producto, proceso o servicio" (Robbins \& Judge, 2011, p. 603). De esta forma se observa que la innovación es llevar a cabo actividades o cosas de una manera diferente. La actitud emprendedora puede definirse como una conducta permanente de administrar los recursos para generar resultados según la actividad en que se desarrolla (Quintero, 2007)

Señala el Global Entrepreneurship Monitor (2007), los emprendedores mexicanos deben plantear sus modelos de negocios con una visión que los lleve a competir en los mercados internacionales y en las instituciones educativas se debe de formar el capital humano integral. Es decir, proporcionar conocimientos y valores durante el proceso educativo, por lo que se han multiplicado en el país varias redes de incubadoras y aceleradoras de negocios, tanto públicas como privadas, que hacen un buen trabajo, pero no es necesario pues el cambio debe de iniciar desde las primarias y terminar con la facilidad de empleo, vía visión integral que dejaría de hacer el gobierno un cómplice del poco acceso al mercado.

México ya tiene los elementos para la estabilidad económica por lo que resulta necesario cambiar esas condiciones hacia la productividad. Para hacer la transición de un sistema oligárquico hacia un buen capitalismo, se necesitan políticas públicas que impulsen el emprendedurismo con cambios legales, institucionales y de impuestos. La meta final es lograr que la entrada y la salida del mercado sea sencilla, asegurar la competencia y desalentar la corrupción. Los emprendedores son la respuesta a los oligopolios, pues hacen el mercado más competitivo. Para crear una economía emprendedora en México se recomiendan: facilitar la apertura de nuevos negocios, recompensar el crecimiento, crear leyes antimonopolios y fomentar el comercio internacional.

\section{CONCLUSIONES:}

- Los emprendedores constituyen uno de los factores de mayor dinamismo que estimulan las actividades productivas de mayor valor agregado, desarrollo económico y social de un país. Al igual que el capital financiero, el capital humano y el capital físico, el empresariado en todas sus dimensiones es una fuente de crecimiento, ya que genera desarrollo económico y genera riqueza al país.

- Al respecto, México debe de impulsar el movimiento emprendedor para que genere empleo, distribución del ingreso, productividad e innovación a las micro y medianas empresas y referenciarse con otros países de las acciones que han realizado y adoptar algunas prácticas de aquellos líderes en el tema del emprendimiento de alto impacto ya que son fundamentales para el desarrollo económico del país.

- La formación por competencias debe de integrar los saberes y la integración practica de dichos saberes a la vida diaria de manera adecuada y en un marco determinado por sólidas bases ética y moral. Los elementos que integran una competencia en general son saber, saber hacer y saber ser.

- Con respecto al sistema educativo es importante consolidar un programa permanente y transversal en el sistema educativo del país, desde el nivel básico hasta el nivel superior orientado a fomentar la cultura emprendedora; además vincular a los centros educativos superiores al sector productivo, económico y social.

- Algunos obstáculos que deben de superarse son la falta de cultura empresarial, falta de financiamiento, altas cargas fiscales, burocratismo gubernamental y la falta de una estrategia nacional que promueva al emprendimiento, la creación de empresas y el trabajo autónomo.

- El mayor reto del emprendedurismo en México lo tienen las universidades quienes albergan millones de estudiantes en los cuales se debe sembrar la inquietud de desarrollar proyectos viables económicamente y socialmente responsables.

\section{REFERENCIAS:}

Acosta, M. (1998). Un proyecto de vida para directores. Planeación de vida y carrera de trabajo. $2^{\mathrm{a}}$ edición. México. Tecnológico de Monterrey.

Arboleda, O. \& Zabala, H. (2011). Condiciones clave para el éxito y sostenibilidad de los emprendimientos solidarios de Medellín. Semestre Económico, (14), 28, pp. 77-94. Consultado el 06 de junio de 2016 [Disponible en]: 
http://www.redalyc.org/articulo.oa?id=165022468 006.

Bargsted, M. (2013). El emprendimiento social desde una mirada psicosocial. Civilizar. Ciencias Sociales y Humanas, (13), 25, pp. 121-132. Consultado el 12 de junio de 2016 [Disponible en]: http://www.redalyc.org/articulo.oa?id=100230029 007.

Borjas, L. (2003). Espíritu empresarial. Creatividad empresarial. Un nuevo reto. Revista Universidad Metropolitana. Vol. 3, No. 2 (Nieva serie), pp. 133-152.

Bunk, G.P. (1994). La transformación de las competencias en la formación y perfeccionamiento profesionales de la RFA. Revista Europea de Formación Profesional 1, pp. 8-14.

Castillo, A. (1999). Estado del arte en la enseñanza del emprendimiento. Programa emprendedores como creadores de riqueza y desarrollo regional Intec. Chile. Intec.

Coyle, D. (2009). Las claves del talento. Barcelona, España: Editorial Zenith.

Curto, M. (2012). Los emprendedores sociales: innovación al servicio del cambio social. Cuadernos de la Cátedra "la Caixa" de Responsabilidad Social de la Empresa y Gobierno Corporativo, 13. Consultado el 10 de junio de 2016 [Disponible en]:

http://www.iese.edu/es/files/Cuaderno\%2013_tcm 5-75666.pdf

Dantus, M. (2013). México y el emprendimiento en su mejor momento. Dirección de Desarrollo Económico. H Ayuntamiento de S.L.P. en línea consulta el 09 de septiembre del 2016. Disponible en http://de.municipiodes/p.gob.mx/mexico-y-elemprendimiento-en-su-mejor-momento/

Díaz-Barriga, A. (2009). Pensar la didáctica. Buenos Aires: Amorrortu.

Drucker, P. (1986). La innovación y el empresario innovador. Editorial. Norma. Colombia.

Duarte, T. \& Ruíz, M. (2009). Emprendimiento, una opción para el desarrollo. Scientia Et Technica, (15), 43, pp. 326-331. Consultado el 5 de junio de 2016 [Disponible en]: http://www.redalyc.org/articulo.oa?id=849173100 58.
Forgas, J. (2003). Diseño curricular por competencias. Tesis doctoral en ciencias pedagógicas. Instituto Superior Pedagógico Frank País, Santiago de Cuba.

Formichella, M. (2004). El concepto de emprendimiento y su relación con la educación, el empleo y el desarrollo local. Buenos Aires, Argentina. Publicación INTA.

Gámez, J. (2008). El emprendedor, hacia una nueva caracterización en Colombia. Management Revista de la Facultad de Ciencias Empresariales. XVII (29), pp. 17-32.

GEM, (2007). World Economic. Foro.

Gibb, A. (1988). Simulating Entrepreneurship and New Business Development. Ginebra. Oficina Internacional del trabajo.

Global Entrepreneurship Monitor (2007). Determinants in a cross country setting. Journal of Evolutionary Economics. Volume 17. Issue 2, pp.117-131.

Goleman, D. (1999). La práctica de la inteligencia emocional. Editorial Kairos.

Guzmán, A. \& Trujillo, M. (2008). Emprendimiento social revisión de literatura. Estudios Gerenciales, (24), 109, pp. 105-125. Consultado el 3 de junio de 2016

[Disponible en]:http://www.icesi.edu.co/revistas/index.php/est udios_gerenciales/article/view/278/276

Jericó, P. (2006). No miedo: en la empresa y en la vida. Barcelona, España. Alienta editorial.

Kirzner, I. (1997). Entrepreneurial Discovery and the Competitive Market Process: An Austrian Approach. Journal of Economic Literature, 35 (1), pp. $60-85$.

Levy-Leboyer, C. (1997). Gestion por Competencias. Barcelona: Gestión 2000. Recuperado el 12 de agosto del 2016 de: http://sht.com.ar/archivo/temas/competencias.htm

McClellan, D. C. (1989). Estudio de la motivación humana. Madrid. Editorial Narcea.

Mercader, V. (1998). Gerencia de la vida. Caracas, Venezuela. Editorial TORVIC. 
OCDE, (2005). Definición y selección de competencias clave (Deseco). Resumen ejecutivo. (Versión electrónica). Recuperado el 12 de septiembre del 2016 de: http://www.pisa.oecd.org/dataoecd/47/61/350703 67pdf.

OIT (1993). Formación profesional. Glosario de términos escogidos. Ginebra. Cinterfor (37).

Orrego, C. (2008). La dimensión humana del emprendimiento. Revista Ciencias Estratégicas, (16), 20, pp. 225-235. Consultado el 26 de junio de 2015 [Disponible en]: http://www.redalyc.org/articulo.oa?id=151312829 001

Pereira, F. (2003). Reflexión sobre algunas características del espíritu emprendedor Colombiano. Revista Econ. Gest. Desarrollo Cali, Colombia, Vol. 1, pp. 9-26.

Perez-Santamarina, E. (1999). Psicopedagogía de las habilidades sociales. Rev. Educ. Univ. Gr. 12, pp. 45-76.

Perrenoud, P. (2004). Diez nuevas competencias por enseñar. Barcelona, España: Grao

Portillo, M.C. (2001). Habilidades sociales y competencia comunicativa en la escuela. Aula de Innovación Educativa 102, pp. 18-22.

Puchol, L. (2001). El libro del emprendedor. Días Santos. España.

Quintero, C. (2007). Generación de competencias en jóvenes emprendedores. UNAB. Recuperado el 22 de febrero del 2017 de http://www.usmp.edu.pe.recuperado.

Real Academia Española (2014). Diccionario de la Lengua Española. Madrid, España. $23^{\mathrm{a}}$ edición. Asociación de academias de la lengua española (ASALE). Recuperado el 28 de agosto del 2016 en: http:www.competencias/definición.

Robbins, S. \& Jude, T. (2011). Comportamiento organizacional. 14a . Edicion. México, Pearson Prentice Hall.

Rodríguez, C. \& Jiménez, M. (2005). Emprenderismo, acción gubernamental y academia. Revisión de la literatura Innovar. 15 (26), pp. 73-89.
Schumpeter, J.A. (1942). Capitalism, socialism and democracy. Nueva York, NY: Harper Row \& publisher.

Schumpeter, J. (1935). Análisis del cambio económico. Ensayos sobre el ciclo económico. Ed. Fondo de Cultura Económica. México.

Senge, P. (1997). La quinta disciplina. Como impulsar el aprendizaje en la organización inteligente. Barcelona, España. Editorial Juan Graniza, S.A.

Soriano, D.R. \& Huarng, R.H. (2013). Innovation and entrepreneurship in Knowledge Industries. Journal of Business Research 66(10) 1964-1969.

Spencer, M. \& Spencer, M. (1993). Competence at work models for superior performance. John Wiley \& Sons. Inc. Nueva York.

Tobón, S. (2010). Formación integral y competencias. Pensamiento complejo, currículo, didáctica y evaluación. Bogotá: Ecoe.

Torbay, A., Muñoz, M.C. \& Hernández, C. (2001). Los estudiantes universitarios de carreras asistenciales: Que habilidades dominan y cuales creen necesarias para su futuro profesional. Aula abierta, 78.pp. 1-17.

Valdaliso, J.M. y López, S. (2000). Historia Económica de la Empresa. Barcelona. Critica.

Vargas-Hernández, J.G. (2001). Las reglas cambiantes de la competitividad global en el nuevo milenio. Las competencias en el nuevo paradigma de la globalización. Revista Iberoamericana de Educación. ISSN: 1681-5653. No. 25, abril del 2001. Recuperado el 25 de agosto del 2016 de http://www.rioei.org/ revista/lectores_ete.htm.

Zorrilla, J. (2009). Las etapas del empresario moderno. Buenos Aires Argentina. El Cid Editor. 